\title{
Clarifying the Situational Context of a TV Company towards the Design of iDTV Applications
}

\author{
Samuel B. Buchdid, Heiko H. Hornung, Roberto Pereira, \\ and M. Cecília C. Baranauskas \\ Institute of Computing, University of Campinas (UNICAMP) \\ Av. Albert Einstein N1251, Campinas - SP, CEP 13083-852, Brazil \\ \{buchdid, heiko, rpereira, cecilia\} aic.unicamp.br
}

\begin{abstract}
Television has experienced transformations that directly impact the TV companies' production chain. In this sense, digital technology and Interactive Digital Television (iDTV) represent business opportunities in terms of investment spent by broadcasters. In this paper, we investigate the impact an iDTV application might have within a TV company by analyzing a situated context. To clarify the problem, we use the knowledge produced from workshops that were based on the Socially Aware Computing approach and that involved various stakeholders to design an iDTV application in a real context. The analysis is illustrated with the graphical representation of Ontology Charts and Norms projected for the observed organization. The findings indicate organizational changes that both suffer from and cause impact on the design of this kind of application.
\end{abstract}

Keywords: Organizational Semiotics, Semantic and Norm Analysis, Design Process, Interactive Digital TV, iDTV applications.

\section{Introduction}

Terrestrial TV has undergone transformations since its establishment. The first images were in black and white, with poor image and audio quality at the receiving end. Sometime after, analog TV won a new attraction: colors. Color TV was a dream of consumption for most viewers and boosted the reach of TV on society. The last major milestone has occurred with the arrival of Digital TV (DTV). DTV includes transmission and compression of digital signals, receiver processing capability and interactivity, thereby enabling Interactive Digital TV (iDTV) [10]. During this migration process, broadcasters have to adapt constantly in order to both meet the technical needs and please an ever more demanding audience. Hence, the TV companies need to improve their production chain with new methods to produce their programming. Such investments require new business models that justify these changes and bring benefits to broadcasters as well as to the audience. In this sense, the investments on DTV and iDTV should be understood as an opportunity to explore the development of new applications, reorganization of television production chains, generating business and social transformations [9].In fact, TV is a highly social and pervasive technology - characteristics that make it a challenging and interesting field for investments. 
With the arrival of DTV, a new business model emerged, and later iDTV opened up a variety of possibilities for new services for TV [15]. Cesar et al. [7] also draw attention to TV's potential social impact, and suggest research on iDTV that incorporates characteristics of viewers and everyday lives. For Kunert [11], beyond better quality in audio and video, viewers can actually interact with the TV, creating a close communication channel between the viewer and the TV companies. Moreover, in order to bring viewers to TV, Pedrosa et al. [14] consider the use of smartphones and tablets in the interaction with TV.

However, the design of interactive applications could be considered a new component into TV companies' production chains. While on the one hand, TV companies still do not have a culture of developing software systems, on the other hand, the software industry has no experience in producing TV programs. Thus, there is a need for creating a specific process for developing iDTV applications that considers both the particularities of television production and the foundations of software development processes [19]. When the need to design a new technology for a company arises, it seems necessary to understand the context into which the system will be inserted, and the main forces that act on it directly and indirectly. Understanding the forces that govern organizational contexts and identifying ontological relations and norms is necessary for the system to make sense to the company and its various sectors [12].

In this paper, we draw on the knowledge produced through workshops conducted in the practical context of a Brazilian TV company that is about to create its first iDTV application. The workshops were conducted in order to clarify forces that emerge within the practical context of this TV company towards the design of iDTV applications. The workshops were organized and conducted on the grounds of the Socially Aware Computing [2] approach to design, Organizational Semiotics [12, 17] and Participatory Design [16]. We discuss the main findings revealed from the study of Ontological Charts that were created from these situated workshops, and are grounded on Semantic Analysis Method (SAM) and the Norm Analysis Method (NAM). Our goal is to explorer how these methods can help us to understand the organizational context and also to anticipate organizational changes that might have an impact on future investments into the production chain and on the TV company's way of doing business.

The paper is organized as follows: Section 2 introduces the theories and methods that ground our work; Section 3 describes the practices conducted to support a situated and participatory design of iDTV applications; Section 4 presents the Semantic and Norm Analysis to clarify the situational context before and after the introduction of iDTV applications in the TV company production chain, and presents and discusses the main findings. Section 5 presents our final considerations and directions for future research.

\section{Background of the Work}

Organizational Semiotics (OS) understands organizations of people as complex systems of sign processing, and recognizes that a technical system is only part of a wider complex system in which people behave according to an organized system of norms. For this, OS proposes a comprehensive study of organizations on different levels (informal, formal 
and technical), and their interdependencies. According to Liu [12], organizations themselves are information systems, and the organizational functions in these different levels are essential for designing a technical information system for this organization. In the informal level, an organization is composed of social norms that drive people's behavior, perceptions, beliefs, values, customs, habits, culture, etc. In the formal level, an organization has their own rules and bureaucratic procedures to do mechanistic and repetitive tasks. The technical system is a part of the formal level which can be automated.

In order to facilitate a better understanding, development, management and use of information systems, a set of methods known as MEASUR (Methods for Eliciting, Analyzing and Specifying User's Requirements) was developed in OS [17]. In this paper, two of these methods inspired our analysis: Semantic Analysis Method and Norm Analysis Method. The understanding of the design problem in the situated context was supported by practices of Socially Aware Computing [2].

Semantic Analysis Method (SAM) is a method to understand the nature and role of affordances (invariant patterns of behavior) and agents (affordances that can take responsibility both for their own and other affordances) in business systems. A business system could be considered a real information system, which is infinitely complex, and only a part of it can be modeled: just a realization (or an instance) of patterns agents' behavior. In practice, SAM focuses on the responsible agents and their repertoires of behavior. For this, the ontology chart maps the temporal relationships between the agent and affordances [12].

Norm Analysis Method (NAM) is a means to specify the temporal patterns of behavior (the social, cultural and organizational norms) governing the agents' actions in the business domain. Norms are linked to each part of the semantic model as the conditions and restrictions for the accomplishment of affordances. A norm can define responsibility for an agent occupying a certain role inside an organizational context and can specify conditions in which some agent can perform some action inside it. Norms have valid periods of existence and can be further specified in a structured way for being translated into a computable language [12].

Socially Aware Computing (SAC) [2] is a socially responsible, participatory and universal approach to the design of systems. SAC draws on OS $[12,17]$ to understand the context in which the technical system will be inserted and the main forces that directly or indirectly act on it; and on Participatory Design (PD) [16] to involve heterogeneous groups of people, who may influence and/or may be influenced by the problem being discussed, and to understand the situated context.

SAC understands the design of a system as incremental cycles that start from society and cross the informal and formal layers to produce a technical solution for an organization. The movement returns crossing the formal and informal layers alike, and impacting on the society; new incremental cycles may be necessary for the technical system to fit the needs of the organization.

\section{The Situated Study}

The study scenario is EPTV: a Brazilian broadcasting company whose program reaches a region in Brazil that includes 300 cities and more than 10 million citizens [8]. Four participatory workshops were conducted in the situated context of EPTV 
aiming at the design of an iDTV application for the TV program "Terra da Gente" (TdG; "Our Land" in English; [18]). Ten participants directly and indirectly involved in the problem domain (e.g., designer, engineers, researchers, TV program director and interns) participated in these workshops.

The workshops were grounded on the SAC approach [2], which was instantiated for the situated context of EPTV (cf. Fig. 1). In this context, we used artifacts from and inspired by OS, such as the Stakeholders Identification Diagram [13], the Evaluation Frame [1], and the Semiotic Ladder [17], and created new practices for supporting participatory and situated design activities. The activities encompassed (see Fig. 1): A) the problem understanding, the proposal of solutions, and the analysis and organization of requirements for the application to be designed; B) Prototyping activities through an adapted version of the Brain Draw participatory technique; C) The materialization of the final prototype; D) Evaluations by representatives from the target audience, by Human-Computer Interaction specialists, and also in a participatory practice with the workshop participants. These activities contributed to the problem clarification, as well as to the design and evaluation of a prototype for an iDTV application. The interested reader may consult [4], [5] and [6] for detailed results and discussions related to these activities.

In this paper, we use information raised from the discussions during these workshops with the EPTV team in order to illustrate the company's organizational structure behind the TdG TV program. The intention is to show how the company is currently organized and uses efforts of several teams that influence and suffer influences from the TdG program to create a first iDTV application. Moreover, we wanted to prospect, according to the participants' perspectives, which organizational changes in the company might arise from the introduction of an iDTV application in the TdG production chain.

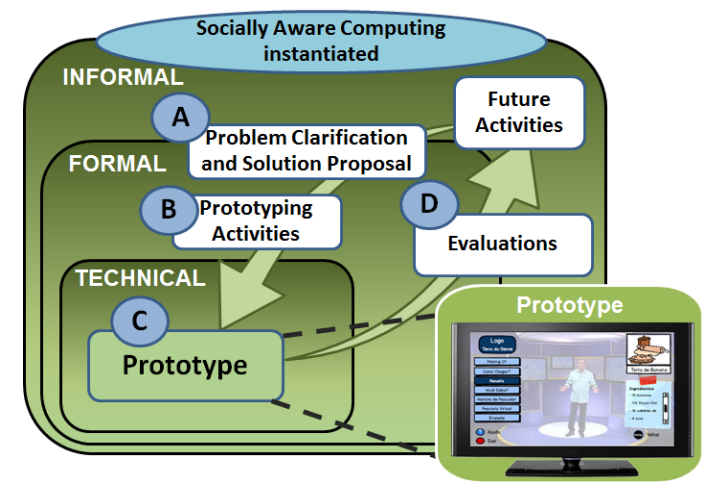

Fig. 1. Situated instance of SAC's meta-model for design

\section{Towards Semantic and Norm Analyses}

The following text is a description of the EPTV company based on the shared knowledge constructed during the workshops with the EPTV team. 
EPTV is an affiliate of a large Brazilian broadcasting company. Currently, EPTV has several teams who work in different sectors that cover the management, production, marketing and transmission of the TV company. EPTV consists of a group with four main stations, and with the support of several rebroadcasting stations, it can cover all its audience with digital and analog programming. EPTV, as well as other affiliates, produces several regional programs (journalism and documentaries) that complement the national programming provided by the parent company, and reaching the local audience and providing marketing opportunities to advertisers and sponsors in the region. EPTV competes with other TV companies in order to attract the audience.

TdG is one of several programs produced by EPTV. TdG's production team works with a cohesive team of editors, writers, producers, designers, technicians and journalists, among other staff members. In addition to the television program, the TdG team also produces a printed magazine and maintains a web portal. Both the magazine and the web portal serve as complementary sources of material for the TdG audience and support TV programs from the parent company. Each member has well-defined rules inside the TdG team. For instance, the Chief Editor is the person who coordinates the production team (e.g., editors, journalists, designers, etc.) of the television program, web portal and magazine. The graphic designer is responsible for the graphic art of the television program and the web portal, and will be responsible for the graphic art of the iDTV application. TdG's team might also be engaged with financial issues such as making feasible the TV show's production costs and minimizing risks raising funding for the program as advertisers and sponsors.

After the program is produced, TdG has the support from the engineering team to transmit the program to its audience. The engineering team is responsible for technical aspects of transmission of several TV programs produced by EPTV, and also for the retransmission of television content that comes from the parent company. Engineering is also responsible for providing technical support (e.g., links between TV companies, TV programs produced for other affiliates) to distribute content among regional branches of EPTV, the parent company and other affiliates. Finally, engineering is responsible for entering data related to the local program, such as electronic programming guide (EPG), software updates and closed caption that complements the TV's schedule and are broadcasted together. The engineering team must also follow the DTV standards because the TV signal must run on several television receivers from different manufacturers. Any improper use might result in the TV signal not running properly or even blocking the receiver.

EPTV works with other relevant teams, e.g., for managing the organization and for hiring staff, but those are out of the scope of this paper. Figure 2 shows the ontology chart created for the EPTV company representing the TdG TV show as the focal problem.

When an iDTV application is introduced into a TV production chain, a development team is required in the TV company to develop the application in accordance with the programming languages defined by the Brazilian DTV standard (ISDB-Tb). For the application to use the interactive channel from connectivity companies, it is also necessary that this new team offers technical support for connectivity problems and management of data received from viewers. This team could be introduced inside EPTV as a separate department, as part of the production team or as part of engineering team. Moreover, it might be an external software company developing services 


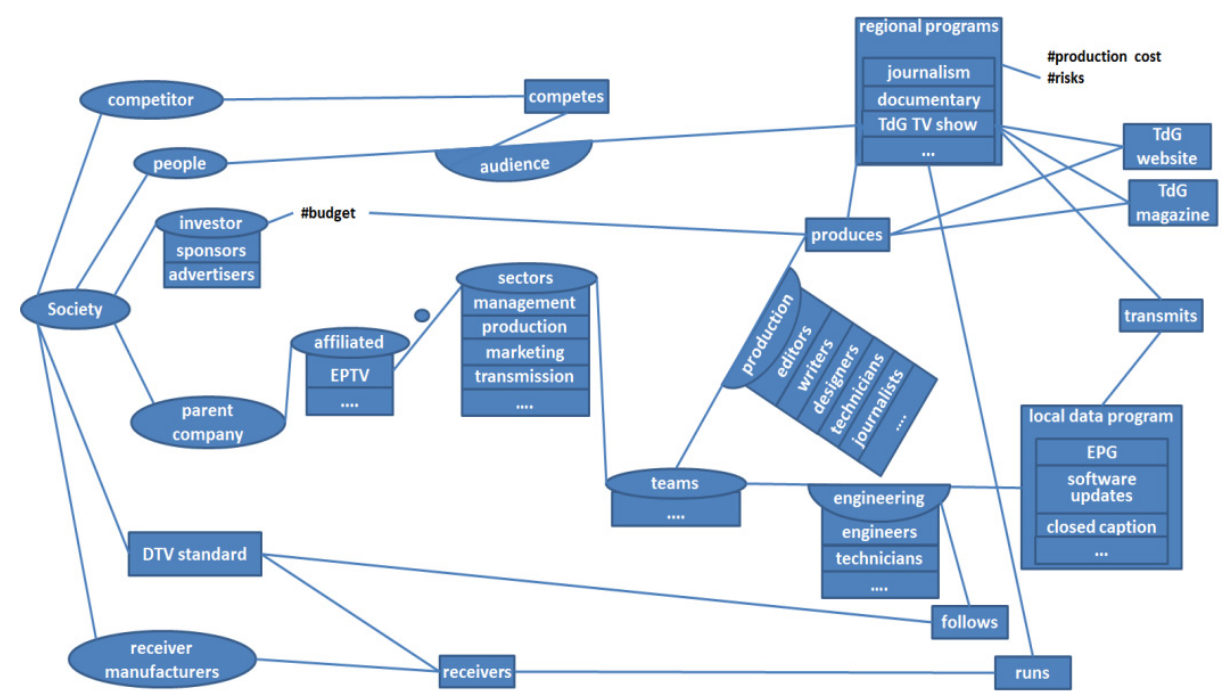

Fig. 2. Ontology Chart of EPTV representing the TdG TV show as the focal problem

for the TV company. Workshop participants suggested that the iDTV design team could be included into the production team but receiving support from engineering.

The engineering team also should propose novel technologies that can be incorporated into the TV company's production and transmission chain generating a relative market advantage. For instance, in the case of an iDTV application, engineering should evaluate solutions (e.g., programing language to be used, how to design the application, how to broadcast it) suitable to the organization's necessities. For engineering, the development of an iDTV application should require resources for purchasing multiplexing and broadcasting equipment to transmit the application with the TV show content. Furthermore, engineering should allocate human resources to operate such transmission equipment and adjust transmission according to the norms from the parent company, e.g., technical norms. The engineering team must also adjust bandwidth for the application transmission, making sure it will not overload the total bandwidth available for the transmission of television content, which includes video, audio and other data types. The period in which the application should be transmitted should also be adjusted according to the duration of the TV show. Thus, the application and its transmission should be of easy operation. Once implanted, these activities may be automated to require less effort from the engineering team.

The production team should consider that the insertion of an iDTV application might increase the TV show audience by people who like new technologies and innovations. Thus, the production team should conduct a careful analysis of the existing and potential future audience. If the iDTV application does not gain public acceptance, then it must be reformulated and not be transmitted together with the TV show. The production team must also produce the informational content of the iDTV application since it complements the current TV show. Similarly, a designer from the TV show should produce the visual iDTV application layout so that the application has the same visual identity as the TV show. The rationale to guarantee consistency between the TV 
show and the application is to promote integration, i.e. by stimulating viewers to access additional information about the show or answering quizzes about the show's content.

The design of iDTV applications involves the allocation of additional resources (e.g., people and money), and this kind of application can introduce risks for the TV company since it is not yet fully consolidated in the market and does not have the full acceptance from viewers yet. Thus, the production team should analyze the viability to produce iDTV applications according to resources from the TV company.

On the one hand, EPTV understands that producing iDTV applications is a necessity from the market because other affiliates and competitors provide this type of application in their schedules. On the other hand, some sponsors and advertisers might not want this type of application because it can distract viewers, reducing their attention to their ads. Finally, as the television content is dynamic, the application development process and the produced application should be easily customizable.

Figure 3 shows the diagram with the partial Ontology Chart after inserting the design of an iDTV application within the chain of production for the TdG TV show at EPTV. The Ontology Chart is instantiated in the focal problem related to the production of the TdG TV show and the design of an iDTV application for it.

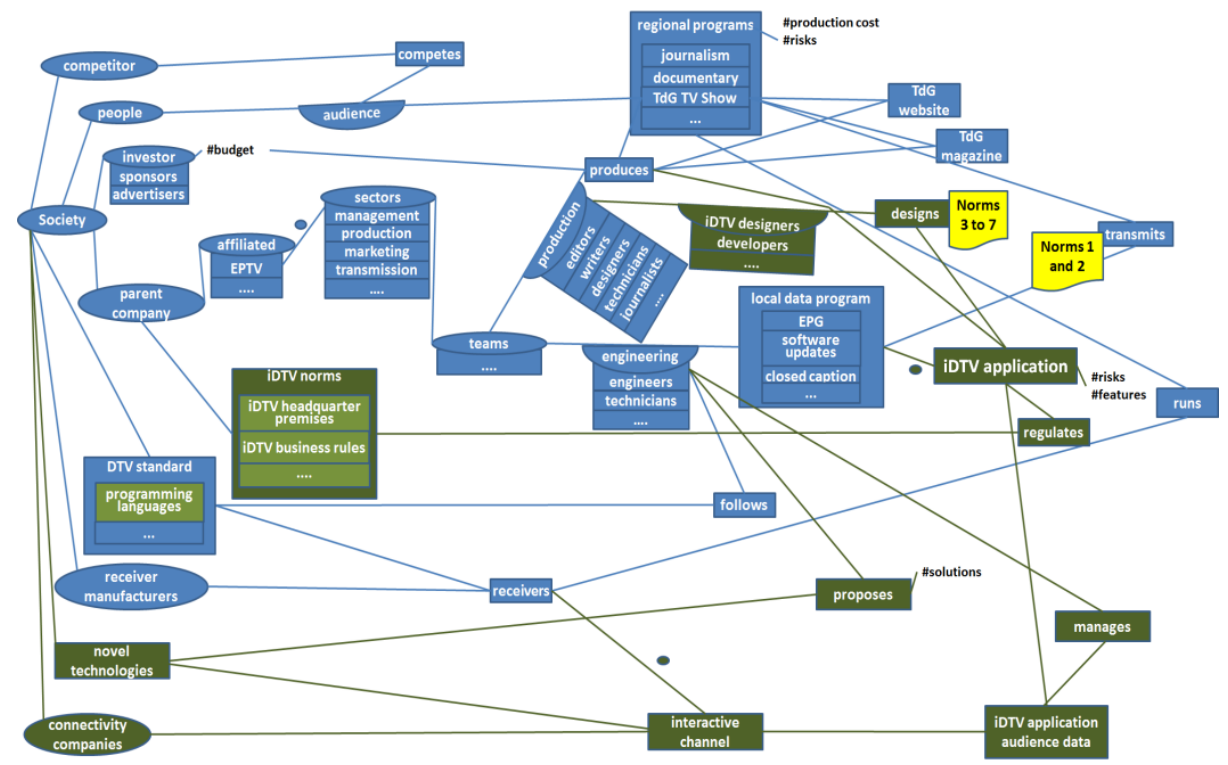

Fig. 3. Ontology Chart of EPTV after insertion of the design of an application iDTV

New norms (previously cited, and shown in Table 1) that impact on these ontological relations emerged (see Fig. 3). These norms should be analyzed by teams to identify the feasibility to produce the iDTV application. To make the dynamic part of the informational system explicit, the rules of behavior used in this paper are structured according to the behavioral norms format [12] "WHENEVER $<$ condition $>$ IF $<$ state $>$ THEN <agent> IS < deontic operator> TO <action>". Table 1 shows some of these norms: the first column contains an identification number to reference the norms in Figure 3. 
Table 1. Some norms for EPTV after insertion of the design of an iDTV application

\begin{tabular}{|c|c|}
\hline Concern & Explanation \\
\hline 1 & $\begin{array}{l}\text { Whenever "an iDTV application needs to be transmitted" if "it is associated with a } \\
\text { TV Show" then "the engineering team" is "obliged" to "adjust bandwidth and } \\
\text { transmission time according to the duration of the TV Show" }\end{array}$ \\
\hline 2 & $\begin{array}{l}\text { Whenever "an iDTV application needs to be transmitted" if "it cannot spend a lot } \\
\text { of resources" then "the engineering department" is "permitted" to "facilitate or } \\
\text { automate the transmission operation" }\end{array}$ \\
\hline 3 & $\begin{array}{l}\text { Whenever "an iDTV application is designed" if "it addresses a diverse target au- } \\
\text { dience" then "the production team" is "obliged" to "carefully analyze the au- } \\
\text { dience" }\end{array}$ \\
\hline 4 & $\begin{array}{l}\text { Whenever "an iDTV application is designed" if "it doesn't have public accep- } \\
\text { tance" then "the production team" is "permitted" to "reformulate it or do not } \\
\text { broadcast it together with the TV show" }\end{array}$ \\
\hline 5 & $\begin{array}{l}\text { Whenever "an iDTV application is designed" if "there are high risks for the TV } \\
\text { company" then "the production team" is "obliged" to "analyze the risks to design } \\
\text { iDTV applications" }\end{array}$ \\
\hline 6 & $\begin{array}{l}\text { Whenever "an iDTV application is designed" if "distract the audience in viewing } \\
\text { ads" then "EPTV" is "permitted" to " customize the iDTV application to prevent } \\
\text { that this happens" }\end{array}$ \\
\hline 7 & $\begin{array}{l}\text { Whenever "an iDTV application is designed for TdG" if "it must be updated } \\
\text { weekly according to the current TV show content" then "the production team" is } \\
\text { "permitted" to "develop easy to use mechanisms for customizing the iDTV appli- } \\
\text { cation" }\end{array}$ \\
\hline
\end{tabular}

\subsection{Synthesis of the Discussion}

EPTV workshops helped to understand in practice that to produce iDTV applications, the production chain requires efforts of several teams from the current broadcaster's production chain. Actually, an iDTV application in a TV show changes the model of developing TV content, and teams are not fully prepared to deal with the changes adequately. In addition, the passive viewer becomes an active user with the arrival of iDTV and should be examined more cautiously. Leaving this responsibility to software companies may not be suitable because of the difference between the TV show and the application domains. Finally, market uncertainties and the viewer's acceptance make it even more difficult to invest in resources for producing iDTV applications. Knowing the TV Company's situated context was a first step to understand these challenges and to propose a design process for iDTV applications that make sense for its different stakeholders, including the final audience.

The ontology and norms analysis performed to map out the organizational structure before and after the insertion of an iDTV application showed substantial changes in the organizational structure of the TV company. New organizational affordances, agents, norms and ontological relations emerged. It also was possible to point out what and where these changes occurred, giving an indication of how they should be taken into account in the adaptation process for inserting the iDTV applications in the TV production chain. 
The ontology relations and norms were used in this paper to understand the situated context from a TV company, and some terms (e.g., EPTV and TdG) appear as realizations or instances of "universals" (a kind of a concept) and "particulars" (a concept). Although different from the proposed in the formal literature [12], these representations were useful to highlight organizational changes from a focal problem within the situated context of a company.

Even though the norms and ontology analysis came from knowledge of the situated workshops, many of the findings pointed out by the analysis may inform other organizations with different organizational structures.

\section{Conclusions}

The development of a TV show can be seen as efforts of skilled individuals working in teams. Each element has an important role in the development phases of the program [3].

In this paper, we analyzed in a situated context what impacts the insertion of an iDTV application might trigger in a TV company production chain. The findings indicate challenges that a TV company must face to restructure its internal production chain in order to support iDTV applications. In this sense, this study might be helpful to anticipate the impact that an innovation (e.g., a new model of the production process) can cause within the organizational system of the TV company. Furthermore, show the knowledge that emerges from an organizational analysis in situated context opens opportunities for future studies in the iDTV field, whether they either theoretical or fundamentally practical.

As future work, we intend to develop a design process for iDTV applications that considers the needs of different teams that compose the TV company in order to propose a process that fits the reality of the TV company, and which also takes into account the needs of a diverse target audience.

Acknowledgments. This research is partially funded by CAPES, CNPq (\#165430/ 2013-3) and FAPESP (2013/02821-1; 2014/01382-7). The authors thank EPTV who collaborated and authorized the use of the documentation in this project.

\section{References}

1. Baranauskas, M.C.C., Schimiguel, J., Simoni, C.A.C., Medeiros, C.M.B.: Guiding the Process of Requirements Elicitation with a Semiotic Approach. In: 11th International Conference on Human-Computer Interaction, pp. 100-111 (2005)

2. Baranauskas, M.C.C.: Social Awareness in HCI. ACM Interactions July-August 2014, 66-69 (2014)

3. Bonasio, V.: Televisão Manual de Produção \& Direção. Editora Leitura, Minas Gerais (2002)

4. Buchdid, S.B., Pereira, R., Baranauskas, M.C.C.: Creating an iDTV Application from Inside a TV Company: A Situated and Participatory Approach. In: Liu, K., Gulliver, S.R., Li, W., Yu, C. (eds.) ICISO 2014. IFIP AICT, vol. 426, pp. 63-73. Springer, Heidelberg (2014) 
5. Buchdid, S.B., Pereira, R., Baranauskas, M.C.C.: Playing Cards and Drawing with Patterns: Situated and Participatory Practices for Designing iDTV Applications. In: 16th International Conference on Enterprise Information Systems (ICEIS 2014), pp. 14-27 (2014)

6. Buchdid, S.B., Pereira, R., Baranauskas, M.C.C.: You Can Interact with Your TV and You May Like It an Investigation on Persuasive Aspects for an iDTV Application. In: Marcus, A. (ed.) DUXU 2014, Part IV. LNCS, vol. 8520, pp. 208-219. Springer, Heidelberg (2014)

7. Cesar, P., Chorianopoulos, K., Jensen, J.F.: Social Television and User Interaction. Computers in Entertainment 6(1), 1-10 (2008)

8. EPTV news portal (2014), http: / / www . viaeptv. com (January 10, 2014)

9. Fernandes, J., Lemos, G., Elias, G.: Introdução à Televisão Digital Interativa: Arquitetura, Protocolos, Padrões e Práticas. In: Jornada de Atualização em Informática do Congresso da Sociedade Brasileira de Computação (JAI-SBC 2004), pp. 1-56 (2004)

10. Gawlinski, M.: Interactive Television Production. Editora Focal Press, Oxford (2003)

11. Kunert, T.: User-Centered Interaction Design Patterns for Interactive Digital Television Applications. Springer, New York (2009)

12. Liu, K.: Semiotics in Information Systems Engineering. Cambridge University Press (2000)

13. Liu, X.: Employing MEASUR Methods for Business Process Reengineering in China, $\mathrm{PhD}$ Thesis University of Twente, Ensgede, the Netherlands (2001)

14. Pedrosa, C., Martins, J.A.C.: Jr, Melo E. L., Teixeira, C. A. C.: A multimodal interaction component for digital television. In: Proceedings of the 2011 ACM Symposium on Applied Computing (SAC 2011), pp. 1253-1258. ACM Press, New York (2012)

15. Rice, M., Alm, N.: Designing new interfaces for digital interactive television usable by older adults. Computers in Entertainment-Social television and user interaction 6(1), article 6, 1-20 (2008)

16. Schuler, D., Namioka, A. (eds.): Participatory design: Principles and practices. Erlbaum, Hillsdale (1993)

17. Stamper, R.K.: Information in Business and Administrative Systems. John Wiley and Sons, New York (1973)

18. Terra da Gente Portal (2014), http: / /www. terradagente. com . br (January 13, 2014)

19. Veiga, E.G.: Modelo de Processo de Desenvolvimento de Programas para TV Digital e Interativa. 141 f. Masters' dissertation - Computer Networks, University of Salvador (2006) 